\title{
An appraisal of end conditions in advanced monotonic and cyclic triaxial testing on a range of geomaterials
}

\author{
Ken Vinck ${ }^{1, *}$, Tingfa Liu $^{1}$, Emil Ushev ${ }^{2}$, and Richard J. Jardine ${ }^{1}$ \\ ${ }^{1}$ Imperial College London, UK \\ ${ }^{2}$ Arup, London; formerly Imperial College London, UK
}

\begin{abstract}
Compressing samples between rigid platens, as in triaxial testing, induce non-uniform specimen stress, strain and pore water distributions. Although well recognised historically, the effects of such platen restraints are often disregarded or overlooked when performing or interpreting monotonic and cyclic experiments. This paper presents an updated appraisal of end conditions based on laboratory experiments run on sand, glacial till, intact and puttified chalk as part of offshore piling research projects. Monotonic and cyclic triaxial tests are reported that incorporated local strain and pore pressure sensors and a range of platen configurations. New insights are reported regarding the small-to-large behaviour and undrained cyclic pore water pressure measurement.
\end{abstract}

\section{Introduction}

The importance of end restraint in conventional triaxial element testing was investigated in pioneering studies by Rowe \& Barden and Bishop \& Green ([1, 2]). Effective end lubrication can be achieved by placing disks consisting of rubber sheet or latex membrane interspersed with viscous grease between the specimen ends and smooth rigid platens. Tatsuoka et al. and Kuwano \& Jardine $([3,4])$ demonstrated how the (i) uniformity of straining could be assessed by reference to any differences between globally and locally measured radial and axial strains, (ii) uniformity could be enhanced in triaxial testing by enlarged lubricated platens and (iii) the lubrication could be optimised by choosing carefully the number of latex membrane layers and the viscosity of the lubricating grease; see Figure 1.

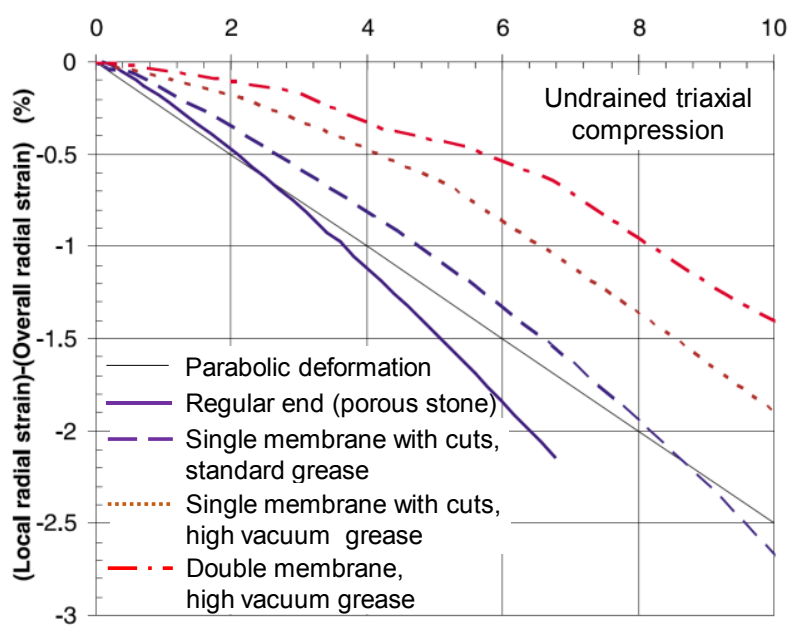

Axial strain (\%)

Fig. 1 Effects of end conditions on the non-uniformity of radial strain observed in undrained triaxial compression tests (Kuwano \& Jardine, 2002)
The implementation of enlarged and lubricated platens is naturally more difficult than adopting "standard" arrangements. Additional trial tests may be required to: (i) optimise the disk configurations and specimen set-up procedures; (ii) avoid undesirable impacts on specimen drainage and stiffness measurements. Lubricated platens add to other aspects of system compliance through their deformation characteristics and the penetration of coarse particles into the layers. Calibrations checks can establish factors to correct for such effects, but the problems are best avoided by measuring strains and pore pressures locally. While such steps may not be common in practice, or applied in all research testing, the increasing interest in applying advanced laboratory techniques to improve geotechnical design poses the need to re-emphasize and quantify the effects of specimen end restraint.

Zdravkovic et al. and Taborda et al. ([5, 6]) demonstrate how the Authors' laboratory tests contributed to the characterisation of site conditions and the calibration of advanced soil constitutive models employed in fully successful 3-D finite element modelling of field tests on large diameter driven piles under lateral and moment loading. The latter formed part of the PISA JIP which developed new paradigms for offshore windturbine foundation design [7]. This research and earlier work by Andersen et al. ([8]) has stimulated industrial interest in advanced laboratory testing to determine with high confidence soil models for offshore and onshore structures subjected to complex monotonic or cyclic loading.

The significant value of advanced laboratory element testing in such applications was outlined earlier by Jardine et al., Jardine and others $([9,10])$. However, the test outcomes rely critically on the procedures followed. Gasparre et al. ([11]) assessed the key technical specifications including load cell connection details, local

\footnotetext{
* Corresponding author: ken.vinck15@imperial.ac.uk
} 
instrumentation, testing control and data acquisition systems required for triaxial tests on stiff clay and demonstrated how these affected the interpretation of prefailure behaviour: poor choices were shown to lead to unrepresentative or even misleading results.

This paper attempts to highlight the potential impacts of end conditions in advanced triaxial testing, drawing on test outcomes from studies on three soils that have distinctly different monotonic and cyclic strength and stiffness behaviours, including those encountered at the two PISA project test sites, which involved (i) fine dense marine sand at Dunkirk and (ii) stiff low plasticity, glacial till at Cowden. We also refer to tests on low-to-medium density chalk, which is the focus of the ongoing ALPACA joint industry project [12]. Illustrative results highlight the impacts of end conditions on:

(1) Linear stiffnesses and non-linear and degradation characteristics;

(2) Uniformity of pore water pressures within specimens undergoing undrained cyclic loading;

(3) Behaviour of structured intact chalk and puttified chalk which exhibit distinctly different and timedependent strength and stiffness features.

\section{End conditions applied in laboratory element testing}

The end conditions applied in general element testing vary between triaxial, Hollow Cylinder Apparatus (HCA) and direct simple shear (DSS) apparatus. Figure 2 demonstrates typical end conditions adopted, which vary according to the needs to either reduce or enhance frictional restraints at the specimen-platen contacts.

Triaxial testing commonly employs rough porous stone(s) placed at the bottom and/or top of the specimen, allowing drainage at one or both ends. As described earlier, lubrication may be achieved by lubricated ends consisting of multiple layers of latex membrane sandwiched with silicone oil or high vacuum grease. Specimen drainage can be either through a small smooth filter-stone set in the centre of the pedestal, or filter papers attached to the specimen and connected to a drainage element placed between the lubricated disk and pedestal. In the former set-up, the central stone could include a dowel that penetrate into the specimen to prevent it from sliding out laterally under loading [13].

In contrast, rough plattens are required in $\mathrm{HCA}$ and DSS tests to apply torsional or horizontal shear stresses during shearing. The specimen ends are commonly in direct contact with regular rough porous stones or sintered bronze rough disks. While in tests on stiff clays or soft rocks (such as chalk) where slippage at the contact interfaces may be a concern, end restraint can be further enhanced by adopting annular disks with thin metal vanes which penetrated into the HCA specimen ends with premade radial grooves, or caps may be manufactured with densely distributed shallow pins that grip the DSS specimen, as illustrated in Figure 2.

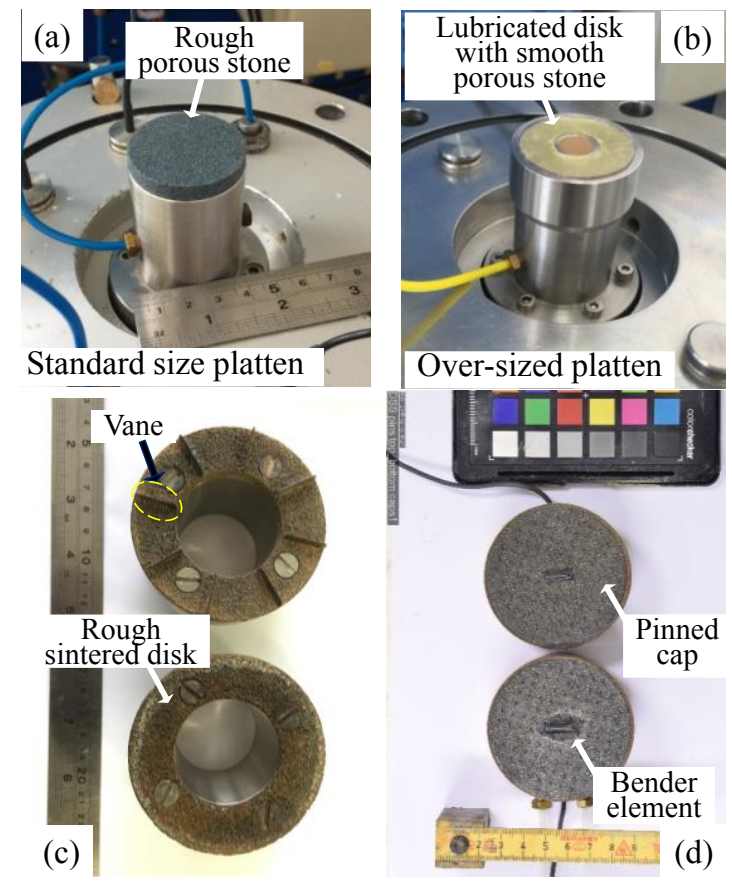

Fig. 2 (a) Triaxial: standard size platen (38 mm OD) with rough porous disk; (b) Triaxial: enlarged platen (43 $\mathrm{mm}$ OD) lubricated with latex membrane disks, pore water draining through a central smoothened bronze porous stone; (c) HCA: rough sintered bronze disk with (top) and without (bottom) gripping vanes; (d) DSS: friction enhanced pinned caps for testing stiff soils at NGI (photo courtesy of Mr. S Quinteros)

\section{Soils and research programme}

The current study focuses on the effects of end conditions on soils' monotonic and cyclic behaviour in triaxial tests. Illustrative results are presented from recent studies reported by Vinck and Liu on Dunkirk sand, Ushev on Cowden till and our ongoing chalk research $([14,15,16])$. The three materials' index properties and the types of apparatuses employed are described briefly below, before discussing the experimental outcomes.

Multiple field pile tests, including the PISA programme, have been conducted in fine siliceous marine sand at Dunkirk in N France. The sand has $D_{50}$ values of around $0.27 \mathrm{~mm}$ and coefficients of uniformity $\left(C_{\mathrm{u}}\right)$ around 1.50. Mineralogical analysis reveals averages of $84 \% \mathrm{SiO}_{2}$ quartz, $8 \%$ Feldspar and $8 \%$ calcium carbonate. Manually removing the larger shell fragments reduced the carbonate fractions present in the tested specimens.

The Cowden till studied by the Authors is a stiff high over-consolidated ratio $(O C R)$, low plasticity glacial till from the Bolders Bank formation. It was sampled at the pile test site employed for the PISA project at Humberside, NE England. Ushev ([16]) reported that the till's plastic and liquid limits span between $14-23 \%$ and $33-60 \%$, respectively. The till is well graded and has a uniform composition dominated by the clay and silt sized matrix material $(\sim 40 \%)$, as well as sand $(\sim 20 \%)$ and gravel $(<10 \%)$ fractions.

The low-to-medium density, high porosity (CIRIA Grade B2/B3) chalk reported here belongs to the Margate and Seaford white chalk formations that were sampled at the ALPACA research site at St. Nicholas- at-Wade, SE 
England [12]. In its intact state, the material manifests unconfined compression strengths (UCS) of around 2.1 $\mathrm{MPa}$ and CPT cone resistance $\left(q_{\mathrm{t}}\right)$ ranging from 5 to 35 $\mathrm{MPa}$. The intact material can, however, be degraded dramatically by pile driving or laboratory compaction at constant water contents. Both processes turn the chalk into to a very soft putty with undrained shear strength $<5$ $\mathrm{kPa}$.

Advanced laboratory testing was performed on all of the above geomaterials, involving advanced triaxial, HCA and DSS devices. Fully instrumented Bishop-Wesley type [17] automated stress-path triaxial cells have been adopted as the main testing equipment. The apparatus and testing environment requirements necessary to achieve suitably high-resolution stress-strain data were summarised by Jardine ([10]), while Ushev and Liu ([15, 16]) present up-to-date assessment of the apparatuses' performance and the key modifications implemented in their recent research programmes.

\section{Test results and discussion}

\subsection{Monotonic drained triaxial tests on Dunkirk sand}

Vinck and Liu $([14,15])$ reported parallel sets of drained monotonic tests on Dunkirk sand that explored the potential effects of end conditions, by considering:

(1) A Semi-Rough (SR) configuration, which consisted of a smooth Perspex cap mounted directly on the specimen top, and a standard rough porous disk placed at the bottom, forming a non-symmetric configuration that is commonly seen in triaxial tests involving one-way drainage;

(2) A Full-Rough (FR) configuration, which was implemented by placing porous stones at both the top and bottom specimen ends, leading to symmetric, although aggravated, constraints at both ends;

(3) An Over-sized fully Lubricated configuration in which lubricated disks were placed at both the specimen's top and bottom ends. Both the polished base stainless pedestal and the smooth Perspex top cap were made with enlarged diameters to accommodate radial strains of up to $13 \%$ before the specimen reached the platen edges.

Two batches of Dunkirk sand were tested that covered specimen initial relative densities from 50 to $95 \%$ and mean effective stress $\left(p_{0}{ }^{\prime}\right)$ of $100-800 \mathrm{kPa}$. The impact of end conditions was examined on the sands' linear and non-linear pre-failure stiffnesses and well as its kinematic yielding; stress-dilatancy and critical state characteristics. The axial strains were determined by high resolution LVDTs that sensed the strain over the central $65 \%$ of the specimen height, well away from the specimen ends.

All the tested specimens had initial height to diameter ratios around 2, fulfilling the criterion set out by Bishop \& Green ([2]) for specimen geometries within which they concluded the effects of end constraints would be negligible. However, consistent dependency on the platen configurations were noted in the specimens' large strain volumetric response. This is demonstrated in Figure 3, taking examples from a suite of isotropically consolidated $\left(p_{0}{ }^{\prime}=100 \mathrm{kPa}\right)$ medium-dense $\left(R_{\mathrm{d}}=50 \%\right)$ and very dense $\left(R_{\mathrm{d}}=95 \%\right)$ specimens. While the latter exhibited largely overlapping $\varepsilon_{\mathrm{vol}}-\varepsilon_{\mathrm{a}}$ trends, the less dense specimen manifested less initial contraction and greater ultimate dilation when tested with rough platens, compared to that seen with fully lubricated platens, suggesting densitydependency of the end restraint effects. Comparison of shear stress-strain traces $\left(q / p^{\prime}-\varepsilon_{\mathrm{a}}\right)$ also indicated that end restraint induced by the rough platens led to higher peak and ultimate shear strengths; the differences were again more prominent in testing on lower density specimens.

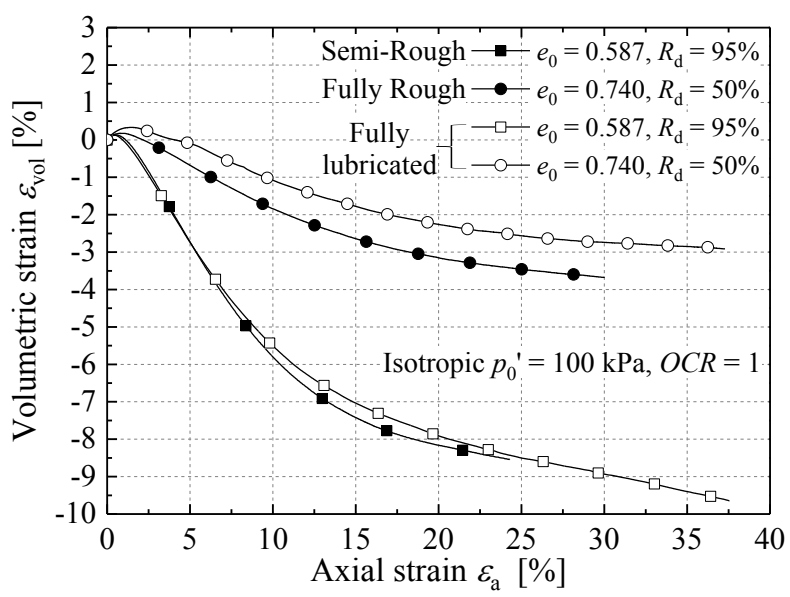

Fig. 3 Effects of platen configuration on the volumetric response of isotropically consolidated $\left(p_{0}^{\prime}=100 \mathrm{kPa}\right)$ mediumdense $\left(R_{\mathrm{d}}=50 \%\right)$ and very dense $\left(R_{\mathrm{d}}=95 \%\right)$ specimens

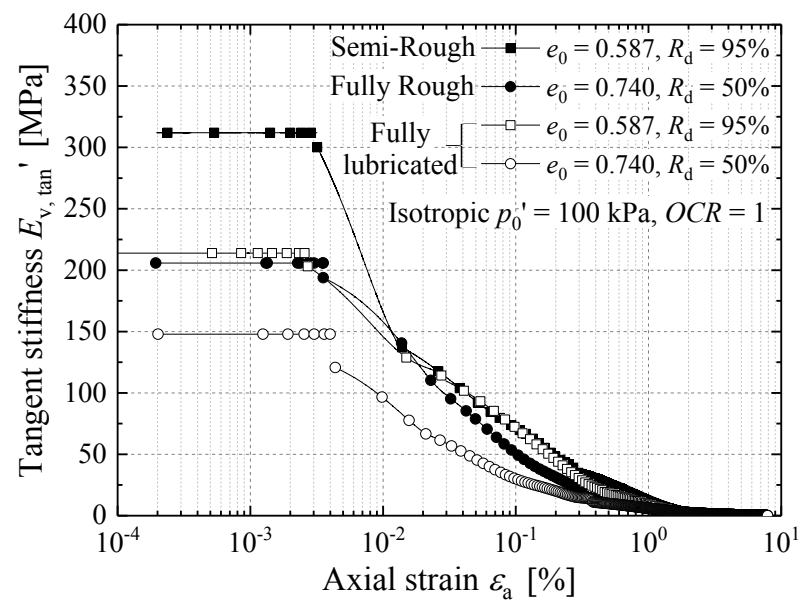

Fig. 4 Effects of platen configuration on vertical tangent stiffnesses $\left(E_{\mathrm{v}, \tan ^{\prime}}\right)$ and the degradation trends

The stiffer responses noted in the rough platen tests were also evident over the small strain range, as demonstrated in Figure 4. The apparent axial Young's moduli $\left(E_{\mathrm{v}, \tan ^{\prime}}\right)$ interpreted from the local strain measurement systems generally increased with the degree of end restraint, although the difference over the nonlinear range became insignificant with the very dense specimen tests after axial strain exceeded $0.01 \%$. The above results, however, suggested that the sand specimens' central stiffnesses were affected more significantly by end restraints that was believed previously.

Effective lubrication at specimen ends facilitates the specimens' radial deformation (see Figure 1) and 
promotes more uniform stress, strain and pore water pressure distribution within the specimens. This finding had significant implications for Liu's ([15]) drained cyclic triaxial tests on Dunkirk sand, and Ushev's ([16]) undrained cyclic triaxial tests on Cowden till. Figure 5 demonstrates the traces of cyclic axial and radial strains recorded in small amplitude $\left(q_{\mathrm{cyc}} / p_{0}{ }^{\prime}=0.05\right)$ drained cyclic triaxial test on Dunkirk sand. Noting that the amplitudes of the axial and radial strains were around $0.0018 \%$ and $0.0002 \%$, respectively, Liu ([15]) concluded that systematic cycle-by-cycle strain measurements was only achieved in tests that employed fully lubricated platens. Also important was the deployment of highresolution strain sensors that are largely immune from compliance errors, including those induced by lubricated disks, which were most significant in the tests on intact chalk samples, as demonstrated later.

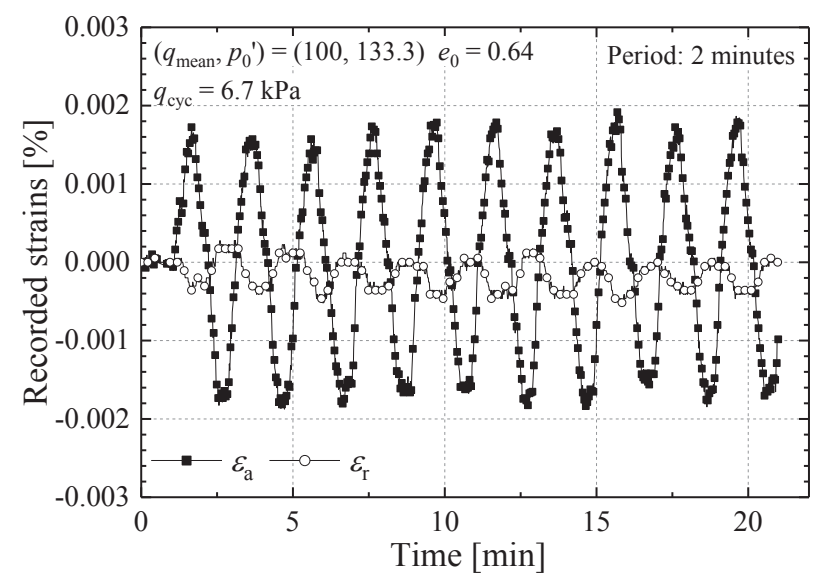

Fig. 5 Cyclic axial and radial strains recorded in a small amplitude $\left(q_{\mathrm{cyc}} / p_{0^{\prime}}=0.05\right)$ triaxial test cycled from quasi- $K_{\mathrm{o}}$ stress condition

\subsection{Undrained cyclic triaxial tests on Cowden till}

Possible non-uniformities of pore water pressure within the larger $(H=200 \mathrm{~mm}, D=100 \mathrm{~mm})$ Cowden clay till triaxial specimens were addressed in Ushev's ([16]) monotonic undrained shear tests by applying suitably slow axial strain rates (5\%/day) during shearing and monitoring mid-height pore pressures locally. Ushev ([16]) reported minimal differences (usually $<1 \mathrm{kPa}$ ) between pore water pressures measured at the specimen mid-height and at the base pedestal even when rough platens were employed. However, more significant nonuniform pore water pressure generation arose in faster undrained cyclic tests. Clear disparities were evident in pore water pressure measurements made at different locations. These persisted to some extent when lubricated platens were implemented to minimise specimen end restraint.

Ushev ([16]) identified pore water pressure distribution by installing multiple miniature probes along his triaxial specimen edges during undrained cycling, adopting the configurations shown schematically in Figure 6. Pore water pressures measured at the base pedestal only became compatible with those from locally instrumented 'mid-height' probes under very slow cycling; periods greater than 30 minutes were required.
However, the probes deployed at different locations gave consistent cyclic peak, trough and mean $(=($ peak + trough $) / 2))$ measurements, as shown in Figure 7 , indicating that uniform pore water pressures were achieved within the main mass of the specimens during cycling.
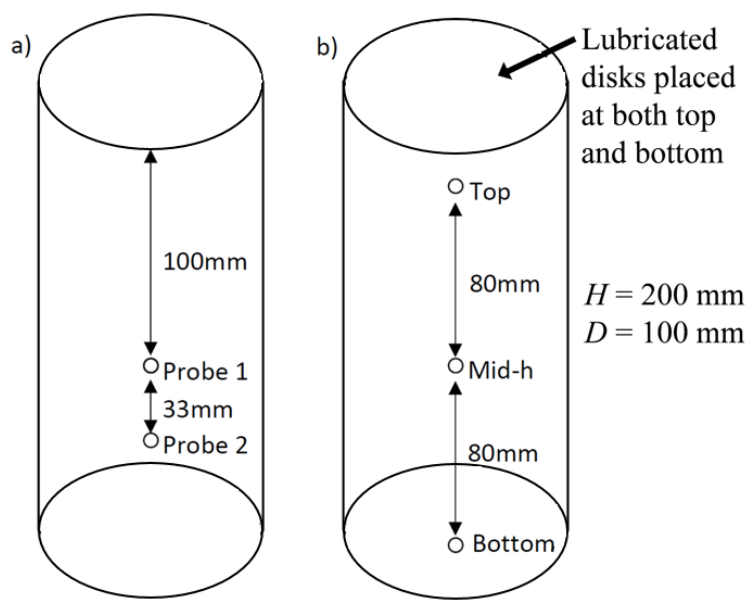

Fig. 6 Schematic configurations of miniature pore water pressure probes deployed to check pore pressure uniformities in undrained cyclic triaxial tests on Cowden till specimens

Further tests were performed with 5-minute periods, deploying three mid-height probes at the specimen edges. As shown in Figure 8, the mid-height probes gave fully matched mean pore water measurements, as well as largely consistent (with deviations $<2 \mathrm{kPa}$ ) peak and trough measurements. The pore water pressure recorded at the pedestal base systematically over-recorded the cyclic pore pressure amplitudes, although the mean values were more consistent with those determined by the local pressure measurements [18].

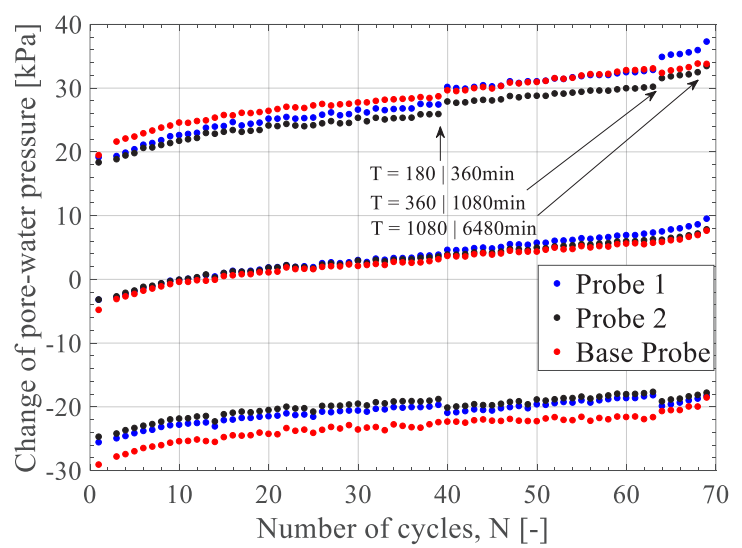

Fig. 7 Trends for cyclic peak, trough and mean $(=($ peak+trough $) / 2)$ pore water pressures measured within the specimen and at base pedestal under relatively slow cycling with $q_{\mathrm{cyc}}=50 \mathrm{kPa}$

Cyclic triaxial, HCA and DSS tests that apply fast cycling have been performed routinely in laboratory campaigns on clay soils to match typical offshore $(0.1 \mathrm{~Hz})$ or traffic $(1 \mathrm{~Hz})$ field loading conditions. However, externally measured pore water pressures may differ significantly from those developed within the specimens 
at such rates. These features are exacerbated in tests that impose significant end restraint (see Figure 2).

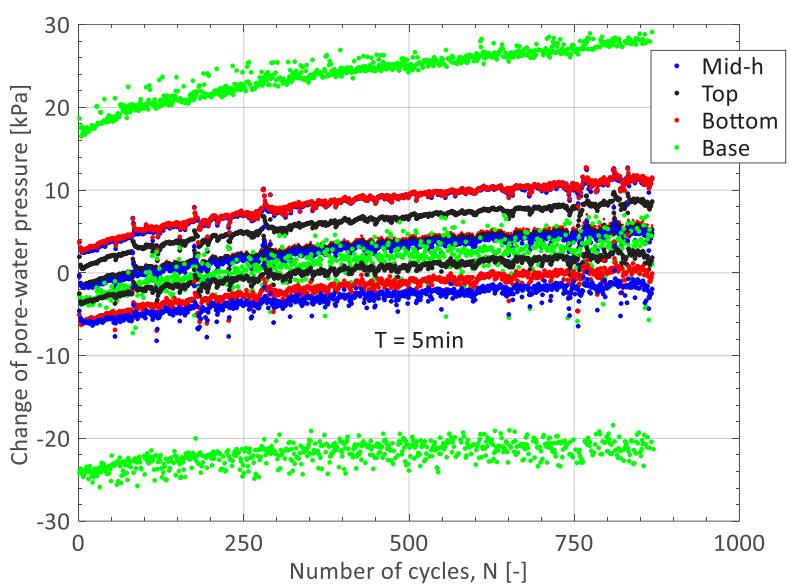

Fig. 8 Trends for cyclic peak, trough and mean (=(peak+trough)/2) pore water pressures measured within the specimen and at base pedestal under cyclic loading

\subsection{Monotonic triaxial tests on intact and puttified Chalk}

As mentioned earlier, undesirable surface irregularities and compliance errors may be induced in triaxial tests that involve lubrication rubber/membrane disks. The surface conditions of the lubrication disks can be improved by preloading the disks or pre-rolling them with a cylindrical rod to squeeze out trapped air bubbles or grease droplets developed between the membrane layers. Careful tolerance checks are recommended for the specimen end flatness's and the perpendicularity of the cylindrical sides, especially when testing stiff brittle soils. Irregularities at specimen ends may cause non-uniform failures when testing such soils.

Axial compliance associated with the loading system and the lubricated disks can be quantified through routine calibration tests performed with a rigid dummy sample, generating results that can, in principle, be applied to correct the displacement measurements made with external strain sensors. However, a better approach is to deploy local strain transducers, which have been used routinely in the current research programmes.

The magnitude of system compliance and the consequent errors in terms of strain and stiffness measurements vary significantly with the tested specimen's properties. Taking examples from tests on a stiff intact chalk and soft puttified chalk (tested after 1 day of ageing) specimens, Figure 9 demonstrates that the system compliance induced by lubricated layers can only be accounted for partly by applying calibrated compliance corrections. The corrected external strain measurement invariably led to underestimated stiffnesses curves. Reliable characterisation of stiffness could only be achieved by deploying high-resolution local strain measurements. However, far less significant differences were noted in Figure 9(b) between the local and external strain measurements made in the puttified chalk test, suggesting that system compliance was far less significant in this specific case.
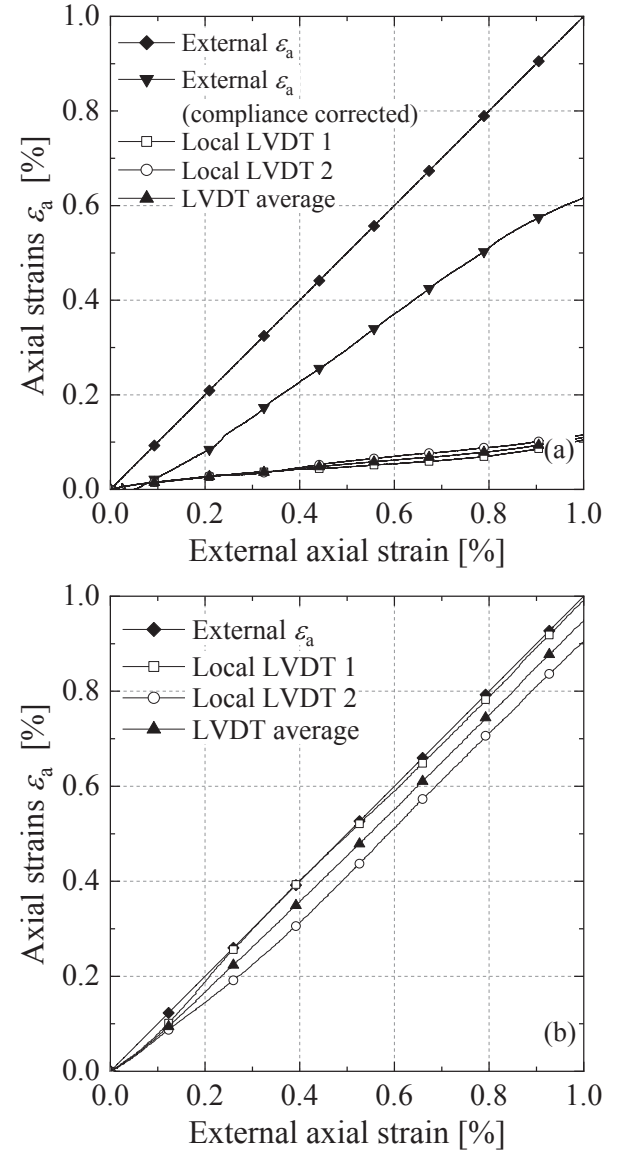

Fig. 9 Axial strains from external displacement transducer and local LVDT measurements for (a) drained triaxial compression of a stiff intact chalk sample and (b) undrained compression of 1 day aged puttified chalk

An extreme case is demonstrated in Figure 10(a) where severe lateral slippage of an intact chalk specimen occurred in a test employing lubricated ends, probably due to lack of sufficient regularity control for the assembled specimen, as well as misalignment between the specimen and loading pedestals. Unrepresentative specimen failure was observed that concentrated at one side of the top end, as shown in Figure 10(b), indicating pedestal-specimen interaction that led to pre-mature failure. Such issues were effectively avoided in later tests by adopting optimised specimen coring and end treatment procedures and implementing tighter tolerance checks on the disks and tested specimens.

Well-characterised shear bands developed within the specimens prepared by the improved procedures that allowed the brittle failure mode (which was accompanied by abrupt post-peak strength reduction) to be tracked, as shown in Figure 10(c).

In contrast to the intact specimens, the puttified chalk samples usually exhibited bulging failure modes, as indicated in Figure 10(d). No significant slippage occurred at the specimen ends when lubricated plattens were employed in these experiments. 


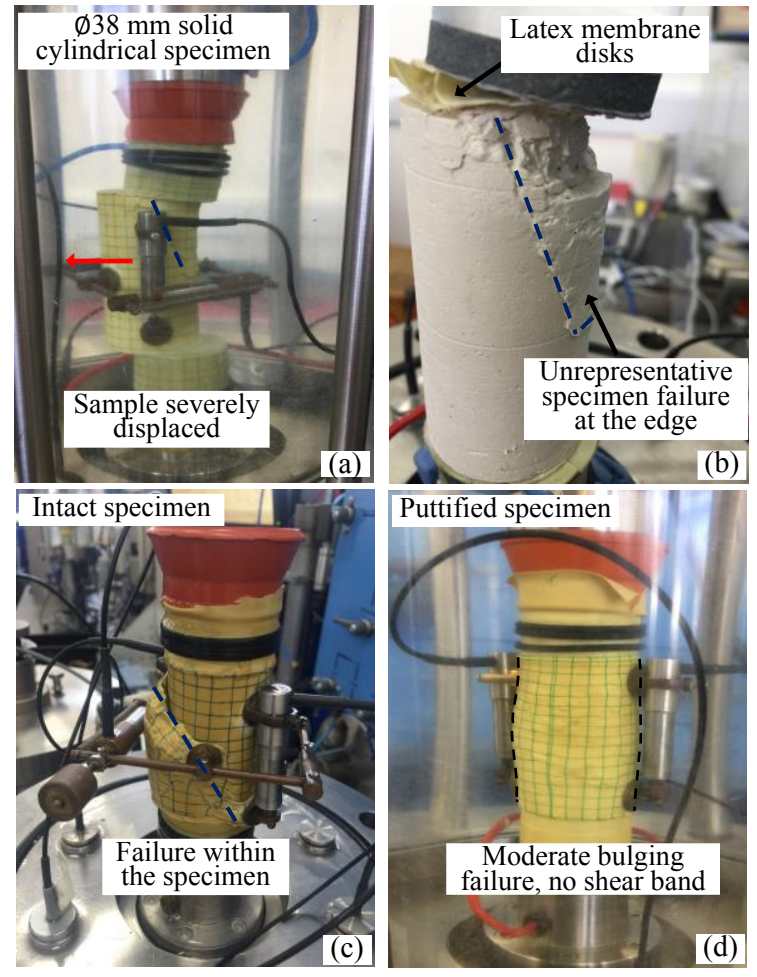

Fig. 10 Failure mode inspection of chalk samples: (a) intact specimen severely displaced due to slippage at the lubricated disks; (b) resultant unrepresentative failure concentrated at the edge; (c) shear band occurred through the specimen in a test with optimised specimen preparation procedures and strict tolerance checks; (d) moderate bulging deformation noted in a puttified chalk sample. Note: all performed with lubricated platens.

\section{Conclusions}

The reported experiments provide clear evidence that conventional rough platens, when applied to triaxial specimens with 2:1 height-to-diameter ratios lead to, results that differ from those obtained in tests employing fully lubricated specimen ends including:

(1) Higher peak and ultimate shear strengths in sand, with the effect being more prominent for lower density specimens.

(2) An over-recording of soil stiffness at small strains

(3) The generation of non-uniform pore water pressures during undrained cyclic loading

The studies also showed that lubricated ends exacerbated overall system compliance and could lead to lateral slippage and pre-mature failure when testing stiffer materials. Trial tests and the use of high-resolution local strain and pore water measurement are vital to optimising the lubricated end arrangements applied to measure strains, stiffness and pore water reliably.

The authors express their appreciation to the Imperial College Geotechnics technical support team and the project sponsors: ESPRC, DEME Group, IC-CSC scholarship and the PISA and ALPACA JIP sponsors (Alstom Wind, Atkins, Cathie Associates, DNVGL, E.ON, EDF, Fugro, GCG, Iberdrola/SPR, Innogy, LEMS, Ørsted, Siemens, SSE, Statkraft, Statoil, Van Oord and Vattenfall). We gratefully thank Mr. S. Quinteros of NGI for his useful discussion points.

\section{References}

1. P. Rowe, L. Barden, J. of the Soil Mechanics and Foundations Division, 90, 1 (1964)

2. A. W. Bishop, G. E. Green, Géotechnique, 15, 3 (1965)

3. F. Tatsuoka, F. Molenkamp, T. Torii, T. Hino, Soils and Foundations, 24, 1 (1984)

4. R. Kuwano, R. J. Jardine, Canadian Geot. J., 39, 5 (2002)

5. L. Zdravkovic, D. Taborda, D. Potts, D. Abadias, H. Burd, B. Byrne, K. Gavin, G. Houlsby, R. J. Jardine, C. M. Martin, R. A. McAdam, E. Ushev, Géotechnique (to be published)

6. D. M. G. Taborda, L. Zdravkovic, D. Potts, H. Burd, B. Byrne, K. Gavin, G. Houlsby, R. J. Jardine, T. F. Liu, C. M. Martin, R. A. McAdam, Géotechnique (to be published)

7. B. Byrne, R. McAdam, H. Burd, G. Houlsby, C. M. Martin, W. Beuckelaers, L. Zdravkovic, D. Taborda, D. Potts, R. J. Jardine, E. Ushev, T. F. Liu, D. Abadias, K. Gavin, D. Igoe, P. Doherty, J. S. Gretlund, M. P. Andrade, A. M. Wood, F. Schroeder, S. Turner, M. Plummer, In 8th Int. Conference on Offshore Site Investigation \& Geotechnics, London, UK (2017)

8. K. H. Andersen, A. A. Puech, R. J. Jardine, In 18th Int. Conference on Soil Mechanics and Geotechnical Engineering (2013)

9. R. J. Jardine, F. C. Chow, R. F. Overy, J. R. Standing, ICP design methods for driven piles in sands and clays. London, Thomas Telford (2005)

10. R. J. Jardine, In 18th Int. Conference on Soil Mechanics and Geotechnical Engineering (2013)

11. A. Gasparre, D. W. Hight, M. R. Coop, J. R. Jardine, Géotechnique, 64, 12 (2014)

12. R. J. Jardine, S. Kontoe, T. F. Liu, K. Vinck, W. B. Byrne, R. A. McAdam, F. Schranz, T. Andolfsson, R. M. Buckley, In $17^{\text {th }}$ European Conference on Soil Mechanics and Geotechnical Engineering, Reykjavik, Iceland (to be published)

13. P. Lade, Triaxial testing of soils, WILEY Blackwell (2016)

14. K. P. A. Vinck, Laboratory testing of Dunkerque sand, MSc dissertation, Imperial College London (2016)

15. T. F. Liu, Advanced laboratory testing for offshore pile foundations under monotonic and cyclic loading, $\mathrm{PhD}$ thesis, Imperial College London (2018)

16. E. Ushev, Laboratory investigation of the mechanical properties of Cowden till under static and cyclic conditions, $\mathrm{PhD}$ thesis, Imperial College London (2018)

17. A. W. Bishop, L. D. Wesley, Géotechnique, 25, 4 (1975)

18. E. Ushev, R. J. Jardine, Géotechnique (to be published) 